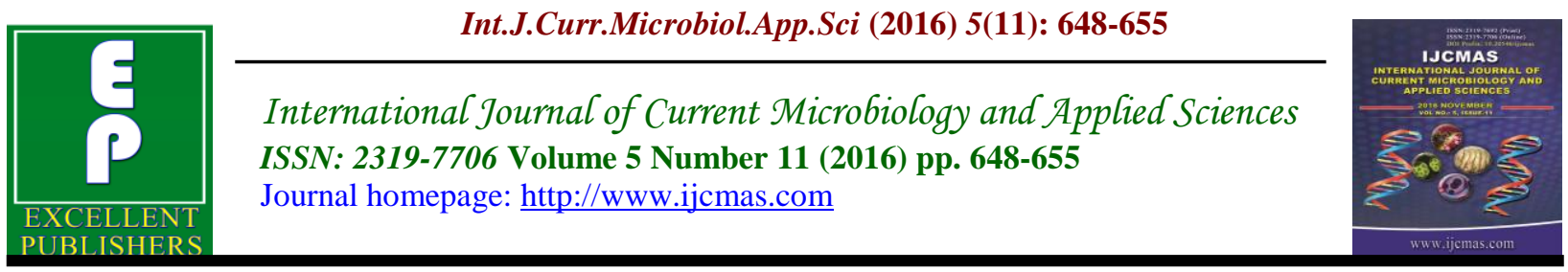

Original Research Article

http://dx.doi.org/10.20546/ijcmas.2016.511.076

\title{
Fluconazole Resistance Pattern of Candida isolates in Clinical Samples by E-Test
}

\author{
V. Mangayarkarasi ${ }^{1}$ *, Kanishka Hrishi Das ${ }^{1}$, Shabana Praveen ${ }^{2}$, \\ V. Chitraleka ${ }^{2}$ and Christopher Amalraj ${ }^{3}$ \\ ${ }^{1}$ Department of Microbiology, SRM medical college hospital and research centre \\ (SRM MCH\&RC), Kancheepuram, Tamil Nadu, India \\ ${ }^{2}$ Department of Cardiology, SRM medical college hospital and research centre \\ (SRM MCH\&RC), Kancheepuram, Tamil Nadu, India \\ ${ }^{3}$ Department of Community medicine, SRM medical college hospital and research centre \\ (SRM MCH\&RC), Kancheepuram, Tamil Nadu, India \\ *Corresponding author
}

Keywords

Candida albicans, Candida non albicans, Epsilometric test, Fluconazole Resistance, Minimum inhibitory concentration.

Article Info

Accepted:

26 October 2016

Available Online:

10 November 2016

\section{A B S T R A C T}

Candida species are often present as commensal organisms in the healthy individuals, the emergence of Candida species which are resistance to fluconazole has become a great concern globally. Aim of this study was to demonstrate fluconazole resistant pattern of Candida species isolated in various clinical samples. This discriptive Study was carried out in SRM Medical College Hospital \& Research centre, Kattankulathur, Kanchipuram, Tamil Nadu, India, between January 2014-2015. Candida species were identified by culture on Sabouraud dextrose agar and confirmed by Gram staining, Germ tube test, Sugar assimilation and fermentation test. Fluconazole resistance was detected by Epsilometric test (ETest) and the minimum inhibitory concentration (MIC) of the Candida species was measured. Chi square test were used for statistical analysis. A total of 98 Candida species were isolated from 168 clinical specimens, $42.8 \%$ of Candida albicans and $57.2 \%$ of Candida non albicans were detected, of the 98 isolates $23.4 \%$ of Candida species were resistant to fluconazole, highest resistance was seen in Candida krusei (90\%). More number of candida non albicans were isolated and showed resistance to fluconazole than candida albicans, hence Candida non albicans should be considered in patient as pathogen and clinically correlate with the infection and presentation of the patient.

\section{Introduction}

Candida species are the normal flora of mucosal cavity, gastrointestinal tract and vagina causes local and systemic infection in immunocompromised patient. There are more than 17 Candida species in which Candida albicans causes more than $90 \%$ of invasive infections. Candida species causes serious debilitating diseases in immunocompromised hosts, resulting in significant mortality, Candida is the fourth most common cause of nosocomial bloodstream infections and the third most 
common cause of catheter associated urinary tract infection infections Prevalence rate of invasive candidiasis is more than $47 \%$ worldwide (Viudes et al., 2002; Wey et al., 1988; Mishra et al., 2007; Pfaller et al., 1998). The emerging pathogen of candida species are often resistant to conventional antifungal therapy, resistance to fluconazole has been reported all over the world (Andes et al., 2004; Sable, 2008). The antifungal resistance pattern of Candida species can be done by either conventional method of in Mueller-Hinton agar (MHA) using different concentration of antifungal agents and Minimum inhibitory concentration (MIC) can be measured by Epsilometer test (ETest) thus the aim of this study was to demonstrate fluconazole resistant pattern by E-test of Candida albicans and Candida non albicans species isolated in various clinical samples collected from patients suspected clinically for candidiasis. This study has been conducted in SRM Medical College Hospital and Research Center, Kattankulathur, Tamil Nadu, India.

\section{Subjects and Methods}

This was a descriptive study. Study was done in SRM tertiary healthcare center, from January 2014 - 2015. 168 clinical samples were collected which include Urine $(n=65)$, the urinary pathogen were proved by isolation from three consecutive samples of a patient with urinary candidiasis to avoid reporting nonspecific organisms. Vaginal swab $(n=35)$, Urinary catheter tip $(n=27)$, wound swab $(\mathrm{n}=20)$, Bronchoalveolar lavage (BAL) $(n=16)$ and Blood $(n=05)$. All samples were collected in sterile container from the patient prior to the antifungal treatment. All samples were examined by direct microscope by Potassium hydroxidmount $(10 \% \mathrm{KOH})$ followed by Gram stain and culture on Sabouraud dextrose agar (SDA) with gentamycin to prevent bacterial contamination and incubated for $48 \mathrm{~h}$ at $37^{\circ} \mathrm{C}$ and $25^{\circ} \mathrm{C}$. Candida species were identified by Gram stain to demonstrate budding yeast cell, hyphae, and pseudohyphae. Germ tube test were performed to differentiate Candida albicans from Candida non albicans. Further speciation of the Candida species were carried out by culture on differential media Chrome agar for detection of colored colonies, Corn meal-tween 80 agar for chlamydospore and blastospore formation. Sugar fermentation and assimilation were done fo identification of Candida species $C$. albicans (ATCC 90028) were used as control strain. We followed Clinical and Laboratory Standards Institute guidelines (CLSI guidelines) M44-A2 protocol for antifungal susceptibility test. MIC of the isolates were determined by using agar based E test method using Mueller-Hinton agar supplemented with $2 \%$ glucose and $0.5 \% \mu \mathrm{g} / \mathrm{ml}$ methylene blue (MHGMB) This media is already proven to work well for determining the MIC of fluconazole by Etest 12. MH- GMB agar plates were inoculated by dipping a sterile swab into the inoculums suspension (adjusted 0.5 McFarland standard i.e. 106 cells $/ \mathrm{ml}$ ) and streaking it along the agar surface in four directions to spread it as a lawn culture. The agar plates were then dried for a minute before applying the $\mathrm{E}$ test strips. The plates were then incubated at $35 \mathrm{oC}$ for $24-48$ hours or until visible growth was seen. The MIC value was read at the point of intersection between the zone edge and the E-test strip. When growth occurs along the entire strip i.e. no inhibition ellipse is seen, the MIC was reported as more than the highest value on the MIC scale. When the inhibition ellipse was below the strip i.e. the zone edge did not intersect the strip, the MIC was reported to be less than the lowest value on the MIC scale (Pfaller et al., 2004). The Candida species were categorized into susceptible (S), susceptible dose dependent (SDD) and 
resistant ( $\mathrm{R}$ ) based on the MIC reading. Isolates with $\mathrm{MIC}<8 \mathrm{mg} / \mathrm{ml}$ were considered to be susceptible to fluconazole, isolates with MIC $>64 \mu \mathrm{g} / \mathrm{ml}$ were considered to be resistant, isolates with MICs between 16-32 $\mu \mathrm{g} / \mathrm{ml}$ were fluconazole susceptible-dose dependent ( $\mathrm{S}$ DD) (Clinical and Laboratory Standards Institute, 2014).

The data were analyzed by using statistical package for the social sciences (SPSS) version 21 (SPSS-Inc., Chicago, IL) for descriptive statistics and Epi-info version 2.2 for chisquare test.

\section{Results and Discussion}

A total of 98 Candida species were isolated from 168 clinical specimens, in which (42.8\%) were Candida albicans and (57.2\%) were Candida non albicans species and there is no statistically significant $(P<0.05$ : $P=0.2)$. Majority of the isolate $(42.8 \%)$ were recovered from urine, $(21.4 \%)$ from vaginal swab, (17.3\%) from catheter tip, (9.1\%) from wound swab, (8.1\%) from BAL and (2.0\%) from blood. Among Candida non albicans species, the most common isolate was C.tropicalis $(21.4 \%)$ followed by $C$. parapsilosis (17.3\%), C.krusei (10.2\%) and C.glabrata (8.1\%) [table1], of the 98 Candida species analyzed for antifungal susceptibility test, (23.4\%) isolate were fluconazole resistance. Fluconazole resistance was found out in more number of Candida non albicans (35.7\%) than in C.albicans $7.1 \%$ and was found to be statistically significant $(P<0.05: P=0.002)$ [table 2\&3]. In this study the Minimum inhibitory concentration of fluconazoles towards Candida isolates represent that 3 out of 42 Candida albican isolates were resistance $\geq 64 \mu \mathrm{g} / \mathrm{ml}$ and 9 were dose dependent, among nine DD isolates two were $16 \mu \mathrm{g} / \mathrm{ml}$, seven isolates were $32 \mu \mathrm{g} / \mathrm{ml}$, 10 isolates were $\leq 8 \mu \mathrm{g} / \mathrm{ml}, 6$ isolates were $4 \mu \mathrm{g} / \mathrm{ml}, 4$ isolates were $2 \mu \mathrm{g} / \mathrm{ml}, 6$ isolates were $1 \mu \mathrm{g} / \mathrm{ml}, 2$ isolates were $0.5 \mu \mathrm{g} / \mathrm{ml}$ and 2 isolates were $0.25 \mu \mathrm{g} / \mathrm{ml}$, highest resistance seen in C.krusei, 9 isolates were $\geq 64 \mu \mathrm{g} / \mathrm{ml}$ out of 10 isolates by E-test [table 4].

In recent years, Candida non-albicans species are emerging as a pathogen. Although Candida albicans has historically been the most frequently isolated species, Candida non-albicans have emerged as important opportunistic pathogen (25). Many studies proved that Candida non albicans causes candidiasis in patients with immunocompromised state, diabetics and prolonged antibiotic therapy (Compte et al., 2004). Candida is the fourth most common cause of bloodstream infections and the third most common cause of catheter associated urinary tract infection infections. Prevalence rate of invasive candidiasis is more than $47 \%$ worldwide. The treatment of invasive candida with Fluconazole drugs and fluconazole resistant Candida species have increased during the past decade, becoming a serious concern (Adhikary et al., 2013; IngeVandenbossch et al., 2002). Higher incidence of candida non albicans ranging from $54-74 \%$ has been seen in various studies. Patients with indwelling urinary catheters, advanced age, diabetes mellitus, and pregnancy were major risk factors associated with candiduria. The urinary pathogens were proved by isolation from three consecutive midstream urine samples of a patient with urinary candidiasis to avoid reporting nonspecific organisms.

In the present study we have isolated 98 Candida species from 168 clinical samples, of that 98 Candida species 56 were Candida non albicans species (57.2\%) and 42 were C.albicans $(42.8 \%)$, the results showed that Candida non albicans were higher, this study was similar to a study conducted by Golia et al stating that Candida non albicans (64.2\%) was higher than Candida albicans (35.7\%) (17). 
Table.1 Number of Candida albicans and Candida non albicans isolates from clinical samples

\begin{tabular}{|l|c|c|c|}
\hline $\begin{array}{l}\text { Total number of } \\
\text { clinical samples(n) }\end{array}$ & $\begin{array}{c}\text { Number of sample } \\
\text { positive for candida } \\
\text { species }\end{array}$ & $\begin{array}{c}\text { C. albicans } \\
\mathrm{n}(\%)\end{array}$ & $\begin{array}{c}\text { Non albicans candida } \\
\mathrm{n}(\%)\end{array}$ \\
\hline Urine(65) & 42 & $13(30.9 \%)$ & $29(59.1 \%)$ \\
\hline $\begin{array}{l}\text { High vaginal } \\
\text { swab(35) }\end{array}$ & 20 & $11(55 \%)$ & $9(45 \%)$ \\
\hline Catheter tip(27) & 17 & $8(47 \%)$ & $9(53 \%)$ \\
\hline Wound swab(20) & 09 & $5(55.5 \%)$ & $4(44.5 \%)$ \\
\hline BAL(16) & 08 & $3(37.5 \%)$ & $5(62.5 \%)$ \\
\hline Blood(05) & 02 & $2(100 \%)$ & 00 \\
\hline Total (168) & 98 & $42(42.8 \%)$ & $56(57.2) \%)$ \\
\hline
\end{tabular}

Table.2 Comparison of fluconazole resistance in Candida albicans and Candida non albicans

\begin{tabular}{|c|c|}
\hline Species (n) & Fluconazole resistance (n and \%) \\
\hline Candida albicans (42) & $3(7.1 \%)$ \\
\hline Non albicans candida (56) & $20(35.7 \%)$ \\
\hline Total (98) & $23(23.4 \%)$ \\
\hline
\end{tabular}

$P<0.005 ; p=0.002$

Table.3 Antifungal susceptibility pattern of Candida isolates to fluconazoles by E-test

\begin{tabular}{|l|c|c|c|}
\hline Isolates & Susceptible $(\leq 8 \mu \mathrm{g} / \mathrm{ml})$ & $\begin{array}{c}\text { Dose depended } \\
(16-23 \mu \mathrm{g} / \mathrm{ml})\end{array}$ & Resistant $(\geq 64 \mu \mathrm{g} / \mathrm{ml})$ \\
\hline C.albicans(42) & $30(71.4 \%)$ & $10(23.8 \%)$ & $3(7.1 \%)$ \\
\hline C.tropicalis (21) & $16(76.1 \%)$ & $01(4.6 \%)$ & $4(19.1 \%)$ \\
\hline c.parapsilosis (17) & $10(58.8 \%)$ & $02(11.7 \%)$ & $5(29.5 \%)$ \\
\hline C.krusei(10) & $01(10 \%)$ & 00 & $9(90 \%)$ \\
\hline C.glabrata $(08)$ & $06(75 \%)$ & 00 & $2(25 \%)$ \\
\hline Total $(98)$ & $62(63.2 \%)$ & $13(13.2 \%)$ & $23(23.4 \%)$ \\
\hline
\end{tabular}


Table.4 Minimum inhibitory concentration of Candida isolates to fluconazoles by E-test

\begin{tabular}{|l|l|l|l|l|l|l|l|l|l|}
\hline \multirow{2}{*}{\begin{tabular}{c} 
Number of Candida isolate \\
\multirow{2}{*}{$\begin{array}{c}\text { tested (n) } \\
\end{array}$}
\end{tabular}} & \multicolumn{9}{|c|}{$\mathrm{MIC}(\mu \mathrm{g} / \mathrm{ml})$} \\
\cline { 2 - 13 } & 0.25 & 0.5 & 1 & 2 & 4 & $\leq 8$ & 16 & 32 & $\geq 64$ \\
\cline { 2 - 13 } & $\mathrm{S}$ & $\mathrm{S}$ & $\mathrm{S}$ & $\mathrm{S}$ & $\mathrm{S}$ & $\mathrm{S}$ & $\mathrm{DD}$ & $\mathrm{DD}$ & $\mathrm{R}$ \\
\hline C.albicans (42) & 2 & 2 & 6 & 4 & 6 & 10 & 2 & 7 & 03 \\
\hline C.tropicalis (21) & 1 & 2 & 1 & 3 & 4 & 5 & 1 & & 04 \\
\hline C.parapsilosis (17) & 1 & 2 & 4 & 2 & 1 & & 2 & & 05 \\
\hline C.krusei (10) & & & & 1 & & & & & 09 \\
\hline C.glabrata (08) & & 1 & 2 & 1 & 1 & & 1 & & 02 \\
\hline Total (98) & 4 & 7 & 13 & 11 & 12 & 15 & 06 & 07 & 23 \\
\hline
\end{tabular}

In the present study, the majority of 42 Candida species were isolated from 65 urine samples, these 42 Candida Species includes C. albicans $13(30.9 \%)$ and Candida non albicans $29(59.1 \%)$. Our observation is similar to that of Alvarez-Lerma et al. and Kauffmann, where $>50 \%$ of urinary Candida isolates belonged to Candida non albicans species (IngeVandenbossch et al., 2002). Very few study reported Candida non albicans as pathogen in urinary samples. In our study we have isolated 29 (59.1\%) and reported Candida non albicans in various clinical samples as pathogen, thus its gives alarm that Candida non albicans are emerging.

The present study tested Candida species isolated from various clinical samples using E-test method to determine their fluconazole resistance pattern. The resistance pattern of fluconazole towards Candida albicans and Candida non albicans using E-test shows that 3 (7.1\%) Candida albicans and 20 (35.7\%) Candida non albicans were resistance to fluconazole showing the MIC of $\geq 64 \mu \mathrm{g} / \mathrm{ml}$. Among the 20 Candida non albicans, $90 \%$ of fluconazole were resistance seen in C.krusei and 29.5\% of fluconazole were resistance seen in C.parapsilosis. The results were compared to another study conducted by Inge Vandenbossch et al., where $>67 \%$ of C.glabrata resistance to fluconazole. Candida non albicans species exhibit resistance to traditional triazole antifungals like fluconazole, voriconazole and itraconazole, the high safety profile of triazoles, in particular fluconazole has led to their extensive use (Theodore et al., 2002; Sachin et al., 2014). Fluconazole resistant Candida non albicans species were more in number in our study which state that there is improper use of antibacterial and antifungal agents in the study area. It is mandatory to know the antifungal susceptibility pattern of fluconazole for effective management of patients, even though newer antifungal agents are available for fluconazole resistance Candida non albicans, they may 
not be affordable for all patients. There has been a rise in the occurrence of candidiasis in our tertiary care hospital that shows a significant shift to higher isolation of candida non albicans species. The high usage of fluconazole appeared to have played a role in this shift, however it may be recognized that other events like patient specific risk factors might have also contributed. Treating Candida nonalbicans infection, fluconazole may fail because of reduced susceptibility, other than fluconazole an echinocandin or amphotericin B may be recommended for Candida non-albicans infection to performing the susceptibility test (Pfaller et al., 2001; Bodey et al., 2002).

Our findings from the in-vitro resistance pattern of the different Candida species implies that antifungal susceptibility should be carried in sample collected from patients with candidiasis and to be standardized.

\section{Acknowledgement}

The author acknowledges Department of Microbiology, SRM Medical college hospital and research center, Kattankulathur, Tamil Nadu, India for allow to conduct this study.

\section{References}

Adhikary, R., Joshi, S. 2013. Species distribution and anti-fungal susceptibility of Candidaemia at a multi super-speciality center in Southern India. Ind. J. Med. Microbiol., 29: 309-11.

Andes, D., Nett, J., Oschel, P., Albrecht, R., Marchillo, K., Pitula, A. 2004. Development and characterization of an in vivo central venous catheter Candida albicans biofilm model. Infect \& Immun., 72: 6023-6031.
Bodey, G.P., Mardani, M., Hanna, H.A. Boktour, M., Abbas, J., Girgawy, E. Hachem, RY. Kontoyiannis, D.P. 2002. The Epidemiology OfCandida Glabrata and Candida albicansFungemia In Immunocompromised Patients With Cancer. Am. J. Med., 112(5): 380-5.

Cannon, R.D., Lamping, E., Holmes, A.R., Niimi, K., Baret, P.V., Keniya, M.V., et al. 2009. Efflux mediated antifungal drug resistance. Clin. Microbiol. Rev., 22: 291-321.

Clinical and Laboratory Standards Institute (CLSI). 2014, Reference method for broth dilution antifungal susceptibility testing of yeasts. Approved standard M100-S24.

Compte, N., Rodriquez-Villalobes, H., Knoop, C., del Marnol, V., De Dobbeleer G, Estenne M, et al. 2004. Uncommon fungal infections after long transplantation. Intern J. Infect. Dis., 8: 511-2.

Deepak juyal et al. 2013. Emergence of Non-Albicans Candida Species in Neonatal Candidemia, North American J. Med. Sci., 5(9): 541-545.

Douglas, L.J. 2003. Candida biofilms and their roles in infection. Trends Microbiol., 11(1): 306.

Espinel-Ingroff, 1997. A. Clinical relevance of antifungal resistance. Antimicrob. Resist., 11: 929-944.

Fleck, R., Dietz, A., Hof, H. 2007. In vitro susceptibility of Candida species to five antifungal agents in a German university hospital assessed by the reference broth micro dilution method and Etest. J. Antimicrob. Chemother., 59: 767-771.

Golia, S., Reddy, K.M., Karjigi, K.S., Hittinahalli, V. 2013. Speciation of Candida using chromogenic and cornmeal agar with determination of fluconazole sensitivity. Al Ameen J. 
Med. Sci., 6(2): 163- 166.

Golia, S., Reddy, M.K. et al. 2013. Specification of candida using chromogenic and corn meal agar with determination of fluconazole sensitivity. Al amen J. Med. Sci., Volume 6, No .2,pg 163-167.

IngeVandenbossch, Mario vaneechoutte, Marleen et al. 2002. susceptibility testing of fluconazole by the NCCLS broth Macrodilution method, E-test and disk diffusion for Application in the Routine lab, J. Clin. Microbiol., 918-921.

Lee, J.S., Shin, H.J., Lee, K., Kim, M.N., Shin, B.M., Uh, Y., et al. 2007. Species distribution and susceptibility to azole antifungal of Candida bloodstream isolates from eight University hospitals in Korea. Yonsei Med. J., 48: 779-786.

Mahmoud, A., Ghanuoum, et al., 1999. Antifungal Agents: Mode of Action, Mechanisms of Resistance, and Correlation of These Mechanisms with Bacterial Resistance, Clin. Microbiol. Rev., 12(4): 501-517.

McGinnis, M., and M.G. Rinaldi. 1996. Antifungal drugs: mechanisms of action, drug resistance, susceptibility testing, and assays of activity in biological fluids, p. 176-211.

Mishra, N.N., Prasad, T., Sharma, N., Payasi, A., Prasad, R., Gupta, D.K., et al. 2007. Pathogenicity and drug resistance in Candida albicansand other yeast species. Acta Microbiol Immunol Hungar. 54: 201-235.

Nelson et al. 1996. P450 superfamily: update on new sequences, gene mapping, accession numbers and nomenclature. Pharmacogenetics. 6:142.

Pfaller, M.A., Diekema, D.J., Boyken, L., Messer, S.A., Tendolkar, S., Hollis, R.J. 2003. Evaluation of the E test and disk diffusion methods for determining susceptibilities of 235 bloodstream isolates of Candida glabrata to fluconazole and voriconazole. J. Clin. Microbiol., 41: 1875-80.

Pfaller, M.A., Diekema, D.J. 2004. Twelve years of fluconazole in clinical practice: global trends in species distribution and fluconazole susceptibility of bloodstream isolates of Candida. Clin. Microbiol. Infect., 10(Suppl 1): 11-23.

Pfaller, M.A., Jones, R.N., Messer, S.A., Doern, G.V., Hollis, R.J. 1998. International surveillance of bloodstream infections due to Candida Species: Frequency of occurrence and antifungal susceptibilities of isolates collected in 1997 in the United States, Canada, and South America for the SENTRY Program. J. Clin. Microbiol., 36: 1886-1889.

Pfaller, M.A., Diekema, D.J., Jones, R.N., Sader. H.S., Fluit, A.C., Hollis, R.J. Messer SA. 2001. International Surveillance Of Bloodstream Infections Due To Candida Species: Frequency Of Occurrence And In Vitro Susceptibilities To Fluconazole, Ravuconazole, And Voriconazole Of Isolates Collected From 1997 Through 1999 In The SENTRY Antimicrobial Surveillance Program. J. Clin. Microbiol., 39(9): 3254-9.

Sable, C.A., Strohmaier, Chodakewitz, J.A. 2008. Advances in antifungal therapy. Ann. Rev. Med., 59: 369-379.

Sachin, C., Deorukhhar, et al. 2014. Nonalbicans Candida Infection: An Emerging Threat, Interdisciplinary Perspectives on Infectious Dis., Volume 34: 615958, 7 pages.

Theodore, C., white et al., 2002. Resistance Mechanisms in Clinical Isolates of Candida albican. Antimicrobial agents 
and chemother., 46(6): 1704-1713.

Vijaya, D., Harsha, T.R., Nagaratnamma, T. 2011. Candida speciation using Chrom agar. J. Clin. Diagn. Res., 5(4):755757.

Viudes, A., Peman, J., Canton, E., Ubeda, P., Lopez-Ribot, J.I., Gobernado, M. 2002. Candidemia at a Tertiary- Care Hospital; epidemiology, treatment, clinical outcome and risk factors for death. Eur. J. Clin. Microbiol. Infect., 21:767-74.

Wey, S.B., Mori, M., Pfaller, M.A. 1988. The attributable mortality and excess length of stay. Arch. Intern. Med., 148: 2642-45.

White, T.C., Marr, K.A., Bowden, R.A.
1998. Clinical, cellular, and molecular factors that contribute to antifungal drug resistance. Clin. Microbiol. Rev., 11: 382-402.

White, T.C., K.A. Marr, and R.A. Bowden. 1998. Clinical, cellular and molecular factors that contribute to antifungal drug resistance. Clin. Microbiol. Rev., 11: 382-402.

Wingard, J.R., Merz, W.G., Rinaldi, M.G., Johnson, TR., Karp, J.E., Saral, R. 1991. Increase In Candida Krusei Infection Among Patients With Bone Marrow Transplantation And Neutropenia Treated Prophylactically With Fluconazole. N Engl. J. Med., 325(18): 1274-7.

\section{How to cite this article:}

Mangayarkarasi, V., Kanishka Hrishi Das, Shabana Praveen, V. Chitraleka and Christopher Amalraj. 2016. Fluconazole Resistance Pattern of Candida isolates in Clinical Samples by ETest. Int.J.Curr.Microbiol.App.Sci. 5(11): 648-655. doi: http://dx.doi.org/10.20546/ijcmas.2016.511.076 